\title{
Morphological Features of Nigerian Pidgin in the Football Commentary
}

\author{
Adesoji Babalola \\ Obafemi Awolowo University, Nigeria
}

\begin{abstract}
The aim of this paper is to analyze and describe the various morphological features that embody commentary in Nigerian Pidgin (NP). The data for this study were drawn from 2018 FIFA World Cup that was hosted in Russia. Pidgin commentary was run and aired on a channel on Digital Satellite Television (DSTV). The pidgin commentaries of the two Semi-Finals between France and Belgium as well as Croatia and England and the Final between Croatia and France were tape-recorded for analysis. The theoretical orientation relies largely on the Item and Process theory (IP) of descriptive morphological analysis popularized. Findings show that reduplication,
\end{abstract}

\footnotetext{
Adesoji Babalola

Lecturer, Department of English, Obafemi Awolowo University, Nigeria

Email: adesojibabalola@oauife.edu.ng
}

Received 13 September, 2020; Revised 16 February, 2021; Accepted 19 March, 2021

Copyright (C) 2021 Language Research Institute, Sejong University Journal of Universal Language is an Open Access Journal. All articles are distributed online under the terms of the Creative Commons Attribution Non-Commercial License (http://creativecommons.org/licenses/by-nc/3.0) which permits unrestricted non-commercial use, distribution, and reproduction in any medium, provided the original work is properly cited. 
compounding and affixation are widely used while blending, clipping and conversion are averagely used in the Pidgin commentary data. It is further revealed that acronymy and abbreviations are uncommon morphological features of NP commentary. The study concludes that the characterization of NP commentary with productive morphological features indicates that the language has the stamina to express all facets of our daily life. It is therefore crucial for the government to support the language with official recognition so that it will continue to contribute significantly to national cohesion in Nigeria.

Keywords: morphological feature, football commentary, Nigerian Pidgin, word formation processes

\section{Introduction}

Nigerian Pidgin $(\mathrm{NP})^{1}$ is an English-based pidgin creole that is widely spoken across Nigeria and could be considered as the country's unofficial national language. NP functions predominantly and informally as a cross-ethnic code of interaction in Nigeria, a country branded by heavy multi-ethnicity and plurilingualism. According to Faraclas (2012: 417), NP is 'the most widely spoken creole language in the world'. Whereas NP is widely used as an L2 by vast majority of Nigerians, it is rapidly creolizing in the Niger-Delta area and in Ajegunle suburb of Lagos as the code is acquired as a first language by children in these regional localities in the country (Deuber 2005, Faraclas 2012, Mazzoli 2017). The popularity of NP among Nigerians has been greatly attested to by Faraclas (2004) as he remarks that NP is spoken by more than half of the country's population and that the

\footnotetext{
1 The following abbreviations are used in this paper: DSTV (digital satellite television), IA (item and arrangement), IP (item and process theory), NP (Nigerian pidgin), PSL (premier soccer league), WP (word and paradigm).
} 
language will continue to increase the number of its speakers as a result of its rising status and deployment in various important domains. Currently, the population of Nigeria is estimated to be over 200 million (Central Intelligence, 2020). The implication therefore is that NP can be said to be spoken by more than 100 million Nigerians. The acceptability of NP across ethic boundaries cannot be detached from the nature of its linguistic simplicity and ethnic nonalignment (Deuber 2005, Mensah 2011). The language does not require any formal education to acquire unlike English and does not belong to any ethnic group in Nigeria.

Thus, Akande (2008) remarks that the current reality in Nigeria is that NP is spoken by Nigerians from diverse occupational backgrounds. Osoba (2015: 132) corroborates Akande by asserting that 'all classes of Nigerians have been noted to use NP in both formal and informal conversations'. Another great strength of NP is its attachment to major Nigerian cities where ethnic diversity is largely concentrated since these cities are major centres of attraction for political and commercial activities as well as employment opportunities for youthful Nigerian population. Osoba (2015) encapsulates the functional spread and social relevance of NP in multilingual Nigeria in the following words:

NP can be described as the widest spoken indigenous language in Nigeria today. From east to west, from north to south, it is the language of choice. Thus it is prevalent in the metropolitan cities such as Lagos, Kano, and Port-Harcourt, especially in the military, police and air-force barracks, stranger communities, and slum areas like Ajegunle and Mushin. In recent times, NP has been used extensively in the broadcast media for news casting, jingles, and all sorts of adverts in other to reach the masses of Nigeria for whom it is either a first, a second, or a third language. Similarly, in most institutions of higher 
learning, it is widely used among students, at both the undergraduate and postgraduate levels, in their informal communication. This is why it is often referred to as Nigeria's unofficial national lingua franca.

(Osoba 2015: 131)

The above assertion captures the power, acceptability and signification of NP in Nigeria and its development into viable varieties such as Waffi (Warri Pidgin), Ajegunle Pidgin, Calabar Pidgin, Port Harcourt Pidgin, Lagos Pidgin and Kano Pidgin which are largely mutually intelligible except for some lexical peculiarity. However, with all these functional implications, NP continues to be neglected by the constituted authority without any official status. This may be connected with its origin as a 'bastardised' contact trade language. The negative attitude towards the language by the political class may likely fade away considering its rapid growth and widespread among Nigerian youth who are dominant in most of the ethnic groups.

Broadly speaking, NP has been described linguistically and sociolinguistically in various contexts and varieties. For instance, Osisanwo (2012: 41) carries out a morphological analysis of advertisement jingles using tape recorded data from Radio and TV stations. His study reveals that NP usage in media advertisement is not only rich morphologically but also functions as the most viable language in advertisement jingles to reach out to the masses and "cater for the demand of both the literate and the illiterate". To support this claim, Osoba (2014: 29) notes that "NP is used extensively in the nation radio networks for advertisement". Also, Durodola (2013) dwells on the role of NP in the popularization of Radio stations that adopt only NP as their language of broadcast and all media programmes. Her argument is that NP contributes immensely to the huge success and popularity enjoyed by such media outlets, in this 
case, Wazobia FM. Akande (2013) argues that NP is the prevalent language in Nigerian hip hop music and this has enabled the hip hop artistes to enjoy huge patronage across ethnic territories leading to high popularity and profitability. Mensah (2011: 214) complements Akande as he notes that NP is the most popular 'language of expression and a form of solidarity' in the Nigerian hip hop world. Scholars such as Akande \& Salami (2010), Amao (2012) Balogun (2013), and Igboanusi (2008) confirm the growing acceptance of the use of NP on various Nigerian campuses particularly in informal socialization among students. This designates that NP could be tagged a 'campus language' since it is highly favoured by students in higher educational institutions. However, many of these scholars hint that majority of students in their survey do not subscribe to the use of NP in the teaching and learning process because of its designation and perception as an informal language of communication.

On the description of regional varieties of NP, Faraclas (1996, 2004 and 2012) and Ihemere (2006) dwell on the general grammatical analysis of Port Harcourt variety of NP. Faraclas (1996) is notably the most all-encompassing descriptive grammar book on NP. The scholarly work describes the functionalities and manifestations of noun phrases, verb phrases, clausal and sentential embodiments of the language and the relevance of NP in Nigeria. It is difficult to talk about the grammar of NP without referencing to the text in that the book lays a strong foundation upon which other grammatical descriptions of NP are built. Another thorough and stimulating book on a variety of NP is Deuber (2005) which pays attention to the general analysis of Lagos Pidgin. Her main focus is to find out whether the type of continuum evidenced between English and Pidgin in Jamaica is applicable between English and NP. Her findings show that such continuum does not exist in Nigeria. Apart from this, Deuber (2005) 
32 Morphological Features of Nigerian Pidgin in the Football Commentary

also describes the grammatical and sociolinguistic features of Lagos Pidgin ranging from grammatical units, gender implication to codeswitching. Mensah $(2011,2012)$ focuses on Calabar variety by analyzing how linguistic items are developing internally in NP to account for lexical development in the code and how such items are deployed to respond to the use of NP in new domains. Osoba (2015, 2018) concentrates on Ajegunle Pidgin by investigating the conversational discourse functions and features as well as power relations among speakers of this variety of NP. While Osoba (2015: 156) remarks that conversations in Ajegunle Pidgin 'exhibit more of informal features or characteristics of human language', Osoba (2018: 1-2)'s study reports that despite the fact that Ajegunle interlocutors share similar social and economic status as ghetto inhabitants, unequal power relations still exist in their verbal interactions with one another.

While there are numerous motivating studies on different aspects of NP, the exploration and linguistic description of NP used in sports domain (which of course is relatively recent) has been neglected in scholarship. This could be premised on the fact the use of NP in football commentary is relatively new. Focusing on the morphological features of NP in football commentary will enable us to highlight and illustrate the grammatical characteristics of the language in sports domain. This is the gap this study intends to fill. As a result, in this paper, we aim to examine the morphological characterizations of NP usage in football commentary as embedded and captured through word formation processes in order to foreground the linguistic peculiarity of this social genre in NP and also discuss how such morphological features contribute to the overall meaning and entertainment of the sports narratives. For decades, national football competitions and football league competitions such as the FIFA World Cup, European Nation's Cup (Euros), Africa Cup of Nations, 
English Premierships, Laliga and Seria A are usually aired on DSTV channels with commentary running mainly in English in Nigeria. However, football fans in multilingual Nigeria cut across different socio-economic and educational backgrounds. As a result, majority of the fans are semi-literates or illiterates who may not understand adequately English commentary. To address this problem, a channel was created on DSTV for NP commentary during the 2018 FIFA World Cup to accommodate and entertain fans of various educational statuses and also make sports discourse more accessible to the Nigerian populace. Since NP is navigating into new domain of use, it is therefore not out of place to examine its linguistic characteristics as intended in this study. Given this background, the next section will further review studies that specifically focus on the grammar of NP.

\section{Literature Review on the Grammar of Nigerian Pidgin}

The syntax and morphology of NP have been explored by a number of scholars (see Mann 1993; Faraclas 1996, 2004; Osoba 2004; Ihemere 2006; Akande 2008, 2010; Osakwe \& Mowarin 2010; Mowarin 2012; Osisanwo 2012). A brief review of some of these works is crucial to this study. For example, Akande (2010) examines the verb phrase in NP and other criterial features and argues that NP is a separate language in its own right because its criterial verb phrases are distinct from those of Standard Nigerian English, and a mismatch between them seems impossible. Mowarin (2012) investigates the use and processes of Wh-interrogatives and interrorgative clefting in NP using Chomsky's Government-binding model. He reports that the 
syntax of the superstrate has been simplified based on the influence of the substrates. He therefore concludes that the substrate languages exhibit a great influence on NP in the area of clefting and Whinterrogatives. Osakwe \& Mowarin (2010) describe the internal structure of the noun phrase in NP. They argue that based on the linguistic influence from the superstrate and the substrates, the noun phrase in NP is syntactically complex and imposing as it functions in various clausal positions in the sentence.

Also, Ihemere (2006) analyses and describes the functionalities of noun clauses in NP. He argues that the only marker of noun clauses is se and that noun clauses can function in various syntactic positions such as the object of the super-ordinate verb and at times as part of an adverbial clause. While Ihemere's conclusion tends to be ample, it is not critical enough as it does not adequately account for nominal clause markers in NP. For instance, apart from the use of se, wetin is also popularly used as a nominal clause marker in NP as in 'Wetin I hear na Ojuelegba' (What I heard is Ojuelegba). Osoba (2004) examines word-formation processes in English and NP and thus reports that compounding and reduplication are the most fertile out of all the processes identified in the two languages. Osoba, however, notes that affixation is not frequently explored in NP compared to English while compounding and reduplication are more used in NP than in English. This means that NP is not rich in the area of inflectional morphology when compared with English in the period of study. Similarly, Mensah (2011) and (2012) examine lexicalization and grammaticalization in NP respectively. He notes that lexical items in NPE are undergoing semantic expansion due to the creativity of the users. He also reports that grammaticalization in NP is not superstrate dependent but a selfindependent evolvement.

Given the volume of literature on the grammar of NP and considering 
the periods of works reviewed so far, it is clear that the linguistic features of NP in football commentary have not been explored. The main reason for this gap is that the domain of football commentary is a relatively recent development in the use of NP. This present paper is therefore distinct from the previous studies reviewed in that it sets the pace in the analysis of NP in football commentary which is a specialized genre with a specialized linguistic structure and register. At this juncture, it is important to review some relevant studies on the language of commentary.

\subsection{Studies on the Language of Sports Commentary}

Sports commentary has been in existence for several decades. It is an essential part of most sports events. It involves live reporting and description of sports activities as they happen on the pitch (Crystal 2003). This form of reporting is usually broadcast during the live matches on the radio or television. In other words, sports commentary is the linguistic description of sports events in real time. A sports commentator who is also known as sportscaster or sport announcer is usually saddled with the responsibility of running the commentary. Mathieson (2016: 59) argues that 'sports commentary is a discourse genre which stands apart from other spoken genres, and even nonsports fans can usually identify it due to its distinctive linguistic and stylistic features'. In the analysis of baseball commentary, Ferguson (1983) hints that the language of commentary is encumbered with the use of present tense, relative clauses and grammatical ellipsis. This is complemented by Quirk et al. (1985: 180) as they note that commentary is full of 'instantaneous present' such as 'Black passes the ball to Fernandez...Fernandez shoots!'. They also remark that instantaneous present relates to a verb which refers to an action that is initiated and completed at speech time. In addition, Aremo (2004: 636) notes that 
football commentaries are loaded with minor sentences whose essential elements have been ellipted such as 'Now to Maradona', and 'Kanu'. Beard (1998: 61) in his book titled The Language of Sport argues that the language of commentary is a specialized one produced through spontaneity and aimed at encapsulating the excitement of sports events and consequently connects with the players, the commentators themselves and the audience.

Also, Pérez-Sabater et al. (2008: 22) survey online football commentaries in English, French and Spanish with a view to identifying oral features and genre blending in football commentaries in the three selected languages. Their findings reveal that the written online commentaries are characterized by features of 'informalisation' and orality which typify spoken genre. To corroborate this viewpoint, Chovanec (2009: 115) pays attention to the linguistic features of livetext commentary or what is generally known as minute-by-minute commentary drawing data from the Guardian newspaper live text online. His findings show that the live-text exhibits some form of colloquialisation in which written genre have features of spoken conversation such as slang, grammatical fillers, commands and rhetorical questions. Dwelling on the lexical features, Mathieson (2016: 60) contends that football commentary has special terminologies which carry context-specific based meanings that are restricted and peculiar only to the genre and such lexical items include 'back-four', 'wall', and 'cross'. From a literary perspective, Chapanga (2004) focuses on the analysis of war metaphors in spoken commentaries of football league in Zimbabwe. He argues that commentators strategically use war metaphors to capture the actions of the players and the demeanour of the spectators to project football as a competitive game in which victory or defeat is an unmarked part of the sports. All these studies are pointers to the fact that the language of commentary is a complex phenomenon worthy of scholarly engagement, and it could 
be more engaging when the language deployed in running the commentary is new to the domain of use as in the case of NP. From this point, we shall proceed to engage the theoretical orientations adopted for our morphological description of NP commentary.

\subsection{Morphological Models: Some Theoretical Background}

There are three relevant and useful models of morphological description and these are IA, IP and WP. As noted by Hockett (1954: 210), a model of grammatical description is 'the frame of reference within which an analyst approaches the grammatical phase of a language and states the result of his investigations'. In IA model, an utterance is viewed as consisting of morphs which are arranged in certain manner relative to one another. As explained by Hockett (1954: 212), IA entails clarifying what constitutes an item and what designates an arrangement, and the task is technically complex and not as easy as it sounds. Bauer (2004: 60) corroborates Hockett by remarking that the IA is a grammatical theory that is concerned with presenting the list of morph making up an utterance and providing some guiding principles for their arrangement. To simplify this theory, Asiyanbola (2012: 72) argues that in IA, 'elements in a linguistic utterance can be arranged syntagmatically, and there is an attempt at representing each word part with a linguistic form'. The implication is that IA embraces the division of words into distinct morphs which are relative to each other such as 'boy $+\mathrm{s}$ (boys)' or 'box + es (boxes)'. However, a problem arises when accounting morphologically for forms of irregular verbs and nouns such as went, sheep, men etc. Scholars in this school of thought devised what is called zero morpheme or $\varnothing$ to account for form that is not overtly present as in ' $m a n+\varnothing=$ men', ' $\mathrm{go}+\varnothing=$ went'. However, this model has been criticized for its complexity, rigidity and lack of clarity in the use of concepts such as 
forms, construction, linear, and arrangement and its inability to satisfactorily account for morphological transformations embedded in irregular nouns and verbs (Hockett 1954, Asiyanbola 2012).

The IP model argues that a linguistic form undergoes a process in which a form could be derived from another. This implies that there are underlying operations leading to processes of derivation of utterance formation. According to Hockett (1954: 227), in IP, a linguistic form is categorized as either 'simple' or 'derived'. While a simple form is a root, a derived form has undergone some processes to produce one or more forms. This means that 'a derived form consists of one or more underlying forms to which process has been applied' (p. 227). The overall aim of IP is geared towards explicating the process a specific root undergoes 'rather than representing a morpheme with a morph as in IA theory' (Asiyanbola 2012: 73). Different morphological processes have been identified under this model including vowel change, consonant change, vowel and consonant change, suffixation, prefixation, suppletion, juxtaposition, infixation and reduplication (Hockett 1947). To reinforce this, Quirk et al. (1985: 1520-1584) list affixation, compounding, conversion, reduplication, clipping, blending and acronymy as essential wordformation processes in English. One interesting remark about IP is that it clearly addresses the morphological transformation of irregular nouns and verbs with its idea of operation and process which has been analysed unsatisfactorily in IA model. Thus, the word wrote in IP can be explained as a derivative of the base write which has undergone the morphological process of past tense. Also, the word men is derived from the root man which can be said to have undergone the process of pluralisation. As grounding and productive the IP model is, it has also been criticized for prioritizing the base over other derived forms without given adequate account of such priority (Hockett 1947). 
However, it seems this criticism is negligible in that the base simply constitutes the semantic core of any morphological form and requires no further clarification.

The WP model was popularly used to analyse Latin and Greek languages which are richly inflectional but rarely applied to English which is an agglutinative language (Asiyanbola 2012: 74). As noted by Bauer (2004), the word serves as the central item in the WP model while other inflectional forms are peripheral. This indicates that the most essential element in WP is the word while different inflections are added to show different grammatical interpretations. While insights are gained from IA and IP models, it is pertinent to hint that our analysis in this study relies largely on the IP theory as explicated in Quirk et al. (1985) and Asiyanbola (2012). That is, we are adopting the IP model for our analysis in this study because it encompasses various morphological processes that are of great interest to us in this study. Also, the IP model is relevant to our analysis in that its explanation on word formation processes foregrounds clarity and is generally acceptable. The theory will therefore enable us to account adequately for the various morphological operations and features used to accentuate linguistic meaning in our data.

\section{Data Source}

The data for this study were drawn from the last 2018 FIFA World Cup that was hosted by Russia. Pidgin commentary was run and aired on a channel on DSTV. The pidgin commentaries of the two SemiFinals between France and Belgium as well as Croatia and England and the Final between Croatia and France were tape-recorded during the live matches at two viewing centres in the city of Ife-Ife, using a 
Kodak voice recorder. After the recording, the data were transcribed on Microsoft Word for analysis. This form of data was preferred because of its live spontaneity, originality and newness. These stages of the World Cup were preferred because of their seriousness and their ability to attract more global attention and because they are often considered the most exciting stages of the prestigious competition. The data were thoroughly studied to identify and describe the various morphological features that are projected through word-formation processes. The analysis relies largely on the IP theory of morphological analysis which prioritizes the internal processes of utterance formation. This indicates that our analysis is theoretically descriptive. In addition, since there is no generally acceptable standardised orthography for NP, we shall retain some of the spellings in the source languages, that is, the superstrate (English) and the substrates (indigenous languages) for easy reading and understanding while we still provide their translations in Standard English.

\section{Data Analysis and Discussion}

In this section, the analyses of the various morphological features used in the data are presented.

\subsection{Reduplication}

Reduplication is a word formation process involving the repetition of a syllable either at the initial, medial or final position in order to form new words as in dilly-dally, flip-flop, and pitter-patter and this is the common practice in English. However, in NP, reduplication usually consists of the repetition of an entire lexical item or doubling 
of the entire base as in small small and fast fast. This is in line with Mensah (2011: 219) as he remarks that 'the only category of reduplication found in NP is complete or total reduplication'. Functionally, reduplicatives in NP are frequently deployed as adjectives and adverbs and less frequently as verbs and nouns in sentential configurations. Examples from the data include:

(1) So dem get plenty plenty experience for world cup pass dem Sweden.

(So, they have a lot of experience more than Sweden at the World Cup.)

(2) She go don arrange better better isi-ewu for them so that them go fit chop and get better coolele mind for this final.

(She would have prepared delicious meal for them to eat so that they would be fit for the final.)

(3) We dey see Ogbonge Ogbonge people them, people wey carry weight for inside this matter of football things.

(We can see great personalities, the dignitaries in the world of football.)

(4) The bross dey score important important goals, na Ivan Perisic be that for you.

(The player scores crucial goals, that is Ivan Perisic for you.)

(5) Sweden dem know how to play big big European countries. (Sweden understand how to play big European countries.)

(6) The main the main actor for that their team... (The most talented player in their team...) 
42 Morphological Features of Nigerian Pidgin in the Football Commentary

As can be seen in examples (1) to (6), the items in bold as in plenty plenty, better better, ogbonge ogbonge, important important, big big and the main the main are clear instances of reduplication. All these reduplicatives are functionally employed as adjectives in the sentences in which they occur in that they pre-modify the nominal phrases experience, isi-ewu, people, goals, European countries and actor respectively. The noun isi-ewu is a "delicacy" that is made from chevon especially with "goat head" and mostly eaten by the Igbos in Southern Nigeria. The commentator deliberately makes reference to isi-ewu to project Nigerian identity with respect to delicacy. It is crucial to note that each of the reduplicatives has its own semantic connotation. For instance, while plenty plenty, better better, and ogbonge ogbonge mean a lot of, delicious and great respectively, important important, big big and the main the main designate crucial, big and talented respectively. Having considered adjectival reduplicatives, let us now focus on adverbial ones as used in some examples drawn from the data:

(7) like play like play na 25 minutes don dey waka pass here On top clock.

(Gradually, 25 minutes has been spent.)

(8) Like play like play, that ball for enter the back of the post (Mistakenly, the ball would have been at the back of the net.)

(9) E go wan talk say like play like play the way wey the first half take start, na so the second half go take start.

(You might want to say that unsurprisingly, the match would continue the way it started in the first half.)

(10) Christiano Ronaldo as him don port las las from Real 
Madrid go Juventus.

(Christiano Ronaldo has finally moved from Real Madrid to Juventus.)

(11) The referee no think am twice himself he just dey take everything soft soft because he never give anybody yellow card here.

(The referee did not doubt it, he is taking everything easy because he has not given any player a yellow card.)

(12) Witsel dey follow the refree reason say that one no suppose be foul bet the referee see am well well.

(Witsel was arguing with the referee that that should not be a foul, but the referee saw it clearly.)

(13) The match wey been dey draw like Ogbona, e be like say the match now, e go con start to dey pick small small joins.

(The match was boring earlier on but it seems it is gradually picking up.)

(14) You know say Sweden go change am for England sharp sharp.

(You know that Sweden would quickly increase the tempo of the match against England.)

As demonstrated above, the phrasal adverbial reduplicative like play like play in examples (7) to (9) projects related but different semantic orientations based on contextual functionality. For instance, in example (7), it means gradually, in example (8) it relates to mistakenly while in example (9) it designates unsurprisingly. What this implies is that many reduplicatives in NP are functionally and semantically 
multidimensional and their interpretations depend largely on contexts of use. In examples (10) to (14), las las, soft soft, well well, small small and sharp sharp mean finally/eventually, easy, clearly, gradually and quickly correspondingly. The use of adverbial reduplicatives is often triggered by lack of markers of intensification or intensifiers in NP. Thus, instead of saying very quick or very fast, one may say quick quick or fast fast as the case may be. This corroborates Osisanwo (2012: 48)'s point of view that reduplication is often deployed for "emphasis" in NP. Apart from these, there are few instances of verbal and nominal reduplictives in the data as shown in the examples below:

(15) Them fit just scatter scatter your defence. (They can dismantle your defence.)

(16) If you dey play with France and you no soji yourself, you fit dey waka waka for field make your leg no touch ball because them sabi hold ball die.

(If you are playing against France and you are not careful, you may be roaming the pitch without touching the ball because they are good at possessing the ball.)

(17) As time don dey go, the French bobo come dey play play with the ball.

(As time is running out, the French players are now toying with the ball.)

(18) Make I no lie you, I no too gbadun him waka waka for this match.

(Let me not deceive you, I do not fancy his wandering around in this match.) 
As shown in examples (15) to (18), there are instances of reduplication such as scatter scatter, waka waka, play play and waka waka which mean dismantle, roaming around, toying and wandering around respectively. Notice that waka waka is used in examples (16) and (18) to refer to the same notion except for a difference in word class. While waka waka is used as a verb in example (16), it is utilized as a nominal item in example (18). This discovery does not only foreground the functional flexibility of reduplicatives but also their structural predictability in NP. Generally speaking, the dominant use of reduplication in NP could be as a result of its high usage in indigenous languages in Nigeria which constitute the substrate of the language. Thus, there is kia kia and rede rede in Yoruba which mean quickly and aimlessly, osizo osizo and ebere ebere in Igbo which mean quickly and gently, and ankeli ankeli and maza maza in Hausa which mean gently and quickly respectively. From all the examples given so far, our observation shows that reduplicatives are more enshrined in adjectives and adverbs than other word classes such as nouns and verbs. As demonstrated in all the selected examples above, it is evident that reduplication in NP commentary is widely used by the commentators to describe football related phenomena including dignitaries, players, goals, duration of actions and sports-like behaviour in order to account for the free-flow of the game. Also, it allows the commentators adequate personal involvement in the diverse moments of the game and enhances their spontaneous linguistic reactions to the happenings on the pitch. This is in accordance with Mensah (2011: 220)'s assertion that reduplicatives in NP have grammatical and semantic value to depict modal meanings. Consequently, reduplication is one of the most viable linguistic tools and a prominent morphological feature in NP commentary. 


\subsection{Compounding}

This word formation process involves the combination of two or more bases or roots to form a lexical unit which is linguistically considered as a single word (Quirk et al 1985: 1569). According to Plag (2003: 12), compounding makes it "possible to combine to two bases". In NP, the major difference between compounding and reduplication lies in the fact that compounds usually consist of two distinct bases while reduplicatives often comprise two unchanged bases. The bases in compounds are usually formed or combined through closeness, hyphenation or separation leading to the various types of compounds such as close, hyphenated and open compounds correspondingly. In other words, compounding in NP tilts towards the superstrate pattern of combining bases for lexical extension. A compound in NP could also be formed by combining two nouns, an adjective and a noun, or a noun and a verb. Examples from the NP commentary data include:

(19) As you dey see am, Mbappe na small pepper, he fit comot water for your eyes.

(As you can see, Mbappe is a tough player, he can make you cry.)

(20) Ngolo Kante wey be double exhaust no go allow you comot for him body.

(Ngolo Kante is a strong player that would not allow you dribble pass him.)

(21) Star boys plenty for this French team.

(There are many talented players in the French team.) 
(22) This match make sense die, he get plenty soko things. (This match is very interesting, it has a lot of great moments.)

(23) The player beg am say make him no vex, tell am say no be badbelle tackle.

(The player apologise that it was not a malicious tackle.)

(24) 90 minutes don complete na jara time na him we just enter so. (90 minutes has been spent, we are in added time.)

(25) The thing be like small shikini tackle but tackle na tackle once the player na him get advantage.

(It looks like a minor tackle, but tackle is tackle once the player has the advantage.)

(26) As Antoine Griezmann cross that ball, Giroudwey be headmaster don set but na Umtiti score am.

(Antonie Griezmann crosses the ball, Giroud who is good at nodding is ready but it was Umtiti that scores the goal.)

(27) Football na jambody game, that one no be foul. (Football is a contact game, that is not a foul.)

(28) This one no be Neymar Wayo-falling, this one na foul. (This is not Neymar's dive, it is a foul.)

(29) This one go be their last bus stop for Belgium as e take be their last bus stop for 1986 .

(This will be the end of Belgium's pursuit of (World up glory) as it was in 1986.) 
48 Morphological Features of Nigerian Pidgin in the Football Commentary

(30) No genge things don happen well well for this game. (No great moments in this match.)

(31) The match dry before but now e don get some kind sengemenge things.

(The match was boring earlier but it has some exciting moments now.)

(32) Last last Dele don nack gbere pass.

(Eventually, Dele has given a poor pass.)

(33) France block industry tight well well, e no easy to enter. (France defence is very tight, it is difficult to penetrate.)

As shown in examples (19) to (33), there are clear instances of compounds in the data. Semantically, the compounds in examples (19) to (23), that is, small pepper, double exhaust, star boys, soko things and badbelle mean a tough player, an energetic player, talented players, great moments and malicious respectively. Also, the compounds in examples (24) to (29) including jara time, shikini tackle, headmaster, jambody, wayo-falling and bus stop designate added time, a minor tackle, a player that is good at scoring goals with header, a contact, a dive and a destination/an end respectively while those in examples (30) to (33) which are genge things, sengemenge things, gbere pass and block industry designate great moments, exciting moments, a poor pass, and defence respectively. While small pepper, double exhaust, star boys, soko things, jara time, shikini tackle, bus stop, genge things, sengemenge things, gbere pass and block industry are clear examples of open compounds, badbelle, headmaster and jambody are good instances of close compounds. 
There is only one example of hyphenated compound which is wayofalling. The inference from this is that open compounds are popularly used in NP commentary based on the examples of compounds drawn from the data so far. In addition, it is observed that all the identified compounds function as nominal items except for badbelle and jambody which are deployed as adjectives in their respective sentential functionalities. Broadly speaking, with the identified compounds, it is evident that compounding is also another productive morphological process deployed in NP commentary to capture various football events and descriptions on the field of play. This finding also agrees with Osisanwo (2012: 47)'s reports that compounding contributes largely to the uniqueness of NP in the aspect of morphology.

\subsection{Affixation}

This is a word formation process involving adding prefixes and suffixes to the base. When it involves putting prefixes at the initial position of the base, the process is called prefixation but if it involves putting suffixes after the base, the process is known as suffixation (Quirk et al. 1985: 1520). Although affixation has been reported to be less productive in NP (Osoba 2004: 245), NP commentary shows that affixation is now a viable word formation process in NP especially with respect to suffixation as there are some interesting instances in the data which include:

(34) The last 3 world cups we don see how e take enter extra time and for the coachy of Croatia Zlatko Dalic him go dey hope say this time around oh them no go enter extra time o.

(We have seen how the last three World Cup (finals) got into extra time but Croatia coach, Zlatko Dalic, would be hoping that this does not get to extra time.) 
(35) If you talk about person wey dey tackle with rough wey dey play ruggedy football you gats talk say na Mandzukic him no different from Diego Coasta wey dey play for Spain. (If you are talking about a player that tackles roughly, that plays rough football, you would say is Mandzukic, he is not different from Diego Coasta who plays for Spain.)

(36) Marcus Rashford, we go soon see am for dis match. The smally from Manchester United.

(We will soon see Marcus Rashford in this match, a young player from Manchester United.)

(37) Them no dey rush them dey take am jejely. (They are not being aggressive, they are playing cautiously.)

(38) Him wan score that one sharperly but the keeper catch am. (He wants to score smartly, but the keeper stops the ball.)

(39) The bros don really show better sabiness. (The player displayed an excellent performance.)

(40) Na him be the bestest player for Sweden. (He is the best player in Sweden.)

(41) The bestest goal, the biggest goal weyem don score for England career because this one na the biggest stage 4 world cup. (This is the best/most crucial goal that he has scored in his England career because this the biggest stage at the World Cup.) 
(42) Mandzukic one of the baddest strikers for inside world of football.

(Mandzukic is one of the best strikers in the world of football.)

(43) Matuidi one player wey be say Didier Deschamps like too much in fact him use him mouth take talk say him go like make Matuidi make he continuate to dey show the same agbakara because he dey remind am of players them like himself. (Matuidi is one player that Didier Deschamps likes a lot and he, in fact, says he would like Matuidi to continue with his diligence as he reminds him of himself.)

(44) Everybody wey dey join hands play for the match or football teams dey make sure say yabbings no dey for inside stadium. (All the players and fans for the match would like to avoid or advise against racist chants/insults at the stadium.)

(45) Olivier Giroud no go fit continuate with that matter because the parapoism of Croatia e be like e dey worry France so far for this match.

(Olivier Giroud cannot progress with the ball because Croatia's teamwork is giving France a tough time in this match.)

(46) Blaise Matuidi him get chance to still help France maintain their Kakarakalisation for mid field.

(Blaise Matuidi still has the opportunity to contribute to France's cohesion in the midfield.)

The identified words in examples (34), (35) and (36) which are coachy, ruggedy and smally mean a coach, rugged and a young player 
52 Morphological Features of Nigerian Pidgin in the Football Commentary

respectively. While the bases of these words are coach, rugged and small accordingly, it is observed that the suffix $-y$ has been added to the bases to pidginize the words and differentiate them from English words. However, one interesting thing about this morphological pidginization is that it may not change the core meanings of the words but only serves as a pidgin marker as used in coachy and ruggedy respectively. The - $y$ morpheme in NP is also capable of changing the word class of a word from an adjective to a noun thereby making it a derivational morpheme as evident in the word small which is an adjective but changed to a noun as result of the addition of the $-y$ suffix. This finding is in line with Mensah (2011: 221)'s statement that 'the suffix -y may often be attached to adjectives to derive nouns which bring about contrastive meaning that are emphatic'. In examples (37) and (38), jejely and sharperly are used to mean cautiously and smartly respectively while the bases of words are jeje and sharp accordingly. Jeje is a Yoruba adverbial or adjectival base-word that has been pidginized with the suffix -ly while still retaining its meaning in the source language. In Yoruba language, you have (Omojeje meaning $a$ gentle guy, or se jeje meaning act gently or cautiously). This indicates that jeje in Yoruba can be deployed as an adjective or an adverb depending on the context of use. On the other hand, sharp is an English adjectival base-word with its stem as sharper but has been pidginized with the suffix -ly to designate different meaning from the source language.

In examples (39) to (42), better means excellent, bestest means best while baddest also means best. In NP, the comparative inflection -er may be used without any see of comparison as evident in the use of better in example (39). In example (40), (41) and (42), the doublesuperlative inflections are evident in bestest and baddest respectively to foreground semantic intensity and emphasis. However, it is 
important to note that the word baddest does not connote any negativity in NP rather it is often used to show how fantastic somebody is at what they do. These examples so far are instances of innovations in NP that are brought to bear through the process of affixation and it shows how different NP affixation is from English inflectional morphology. In examples (43), (44), (45) and (46), continuate, yabbings, parapoism and kakarakalisation are used to mean continue, racist insults, teamwork and cohesion respectively. In example (43), continue is the base but the suffix -ate has been added to make it an NP form without changing the meaning of the word from English. In example (44), yab is the base from NP and usually functions as a verb to mean to insult but has been nominalized with the addition of a derivational morpheme -ing and thereafter takes the -s marker of pluralisation in English to make the word a plural noun. Yabbings therefore could mean ordinary insult or racist insult based on its contextual deployment. In parapoism, parapo is the base from Yoruba language but has been anglicised morphologically with the suffix -ism to form a pidgin word while still maintaining its meaning from the source language. Similarly, in kakarakalisation, kakaraka is usually a verbal root from NP which means to tighten/to secure but has undergone the process of nominalization through the addition of the suffixes -lisation. These morphological borrowings are not unexpected considering the fact that NP is a product of language contact. A general look at examples (34) to (46) shows that the process of affixation is richly adopted through suffixation while prefixation is rarely used in the commentary data, and by extension in NP. The analyses further demonstrate that affixation is a dynamic morphological instrument deployed strategically in NP commentary to indicate nominalization, pluralisation and pidginisation of linguistic resources essential to capture sport-related activities. While affixation might be limitedly used in NP generally, its demand in new domain could be a 
54 Morphological Features of Nigerian Pidgin in the Football Commentary

contributory factor to its adoption in order to express new areas of meanings.

\subsection{Blending}

Blending is another productive process that involves joining the fragments of two words to form a new word. In this process, fragments of two existing words are cut off and joined to create new lexical forms. To put it in another way, "blends ... are amalgamations of parts of different words" (Plag 2003: 13). Furthermore, Quirk et al. (1985: 1583) argue that many blends in English are usually products of advertisements and are consequently "short-lived" and do not survive beyond the context of their origination. However, in NP, blends are integral constituents of the vocabulary of the language. Instances from the data include:

(47) See as him troway that ball.

(Loot at how he lost the ball.)

(48) Time don dey comot small small for Croatia. (Time is running out gradually for Croatia.)

(49) No team dey their domot for this World Cup Final, na no man's land.

(No team is playing in their home country in this World Cup Final, it is no man's land.)

(50) Na French presido be that, him sidon jejely dey happy for him boys.

(That is the French President, he sat down quietly and happy for his team.) 
(51) E be like sey them wan try wunjo the skipo for England. (It is like they are attempting to injure England's skipper.)

As demonstrated in examples (47) to (51), there are instances of blending including troway, comot, domot, sidon and wunjo. Troway is formed from throw and away while comot is formed from come and out. Also, domot is created from door and mouth whereas sidon is created from sit and down. Wunjo is formed from the fragments of wound and injure. In example (47), troway means to throw away or lose something but in example (48), comot means to run out. In examples (49), (50) and (51), domot, sidon and wunjo mean home country, sit down and to injure respectively. In addition, troway, comot, sidon and wunjo are utilized as verbs while domot functions as a noun phrase. It can be argued, therefore, based on the identified examples, that blending occurs more in verb forms than noun forms in NP. From our observation, we can also assert that while blending is a productive process, it is not as ubiquitous as reduplication, compounding and affixation in NP commentary and by extension in NP generally.

\subsection{Clipping}

Clipping constitutes another process in the morphological description of NP. It is a process that involves shortening or deleting parts of the root to create a new word and still maintains the semantic value of the original word (Plag 2003: 13). This subtraction of one or more syllables can be done from any parts of the word and this justifies why Mensah (2011: 225) argues that the chopping off of syllables in the clipping process is arbitrarily done without any generally acceptable customary principles. Examples of clipping in the data are highlighted below: 
(52) Lukaku dey always stand for better posi. (Lukaku is good at positioning.)

(53) Hazard and Lukaku don dey collabo. (Hazard and Lukaku are beginning to collaborate.)

(54) He no dey tire, Kante! Play this match 300 minutes he dey there. Just 8 years ago nobody know this bross bet now na one of the bestest mid-fielder for the whole wide world. (Kante! He does not get tired; if the match lasts for 300 minutes, he is still standing tall; nobody knew this player eight years ago but now he is the best mid-fielder in the world.)

(55) See as Oga presido for France Emmanuel dey look as Perisic don equalised against them.

(Look at how the French President is staring as Perisic equalized against them.)

(56) For all the capito for this ogbonge competition, na Modric humble pass.

(Of all the captains at this World Cup, Modric is the humblest.)

(57) The end tory for this final match dey sweet the belle of France fans.

(The end story of the final match makes the French fans happy.)

(58) The defender stand kakaraka, he no gree make Mbape comot for him body.

(The defender stands firmly and does not allow Mbape to dribble pass him.) 
(59) I gbadon this French team, them get many many skipo for this World Cup.

(I like this French team; it is composed of many skippers in this World Cup.)

The lexical items in bold from examples (52) to (59) show that there are clear-cut instances of clipping in the commentary data. The original words from English are position, collaborate, brother, president, captain, story, agree and skipper respectively. However, parts of each of the English words have been truncated to form NP words while still retaining their meaning from the originated language except for bros which means a player and gree which means allow in the contexts of NP commentary. It is further observed that most of the cutting offs occur at the final syllables except for gree whose truncation happens at the initial position. This dominant pattern of final-syllable truncation in NP is similar to the obtainable trend in English. As observed by Quirk et al. (1985: 1580), in English, "the surviving fragment is usually initial and need not constitute either prosodically or semantically the salient part of the original".

\subsection{Conversion}

Another interesting morphological process noticeable in the data is conversion which designates the changing of words from one word class to another without any affixational application. In other words, it is a process of derivation in which a lexical item is functionally converted to another word class without adding an affix (Quirk et al. 1985). Conversion is also known as functional shift or zero derivation. As evident in the data, examples of conversion include: 
(60) Mbape get ginger die, this smally dey always ginger himself for field no be small.

(Mbape has a lot of motivation, this young player always motivates himself on the pitch.)

(61) See as the two bros dey yan together, the third bros don join the yan too.

(Look at how the two players are discussing together, the third player has joined the discussion.)

(62) The bros dey cry as referee blow the final whitle, he go dey think say this one na shame o as France take beat them, but na so France dey shame country for World Cup.

(The player starts to cry as the referee blows final whistle, thinking that it is a shame to lose to France but France is fond of shaming/disgracing countries at the World Cup.)

In example (60), ginger is used as a noun to mean motivation while in the second instance, it is utilized as a verb to designate motivate. In example (61), yan is used in the first instance as a verb to mean discuss whereas in the second example, it is deployed as a nominal item to imply discussion. Also, in example (62), the item shame occurs twice in the sentence functioning as a noun and a verb respectively. And as shown in the translation, the meaning of shame from the source language is retained in NP. This style of changing word class without adding anything to the base is what Plag (2003: 12) refers to as "nonconcatenative" morphological process which is largely manifested through conversion. While our observation shows that conversion is not a dominant morphological feature in the data analysed, it is crucial to attest to its presence in the commentary as done in this study. It is 
also important to hint that acronymy/abbreviation is rarely used in NP commentary. Apart from the word FIFA (Federation International de Football Association), there is no other acronym in the data.

\section{Conclusion}

Football commentary being a new domain of use for NP foregrounds how word formation processes are broadly embraced by commentators to relate new actions, activities and general descriptions within the purview of sports discourse. While NP commentary exhibits high influx of reduplication, compounding and affixation in the data, blending, clipping and conversion appear to be on the average. Acronymy and abbreviations seem to sparsely feature in NP commentary. It is evident that NP commentary accommodates high morphological innovations to project how NP can function freely in new domains of use. We agree with the view of Mensah (2011) that language often develops new linguistic properties morphologically to accommodate diverse areas of meanings which could be cultural, social and political in orientations. The paper concludes that the characterization of NP commentary with productive morphological features indicates that the language has the stamina and vivacity to express all facets of our daily life. It is therefore crucial to address the educational and political marginalization of NP so that the language will continue to contribute significantly to national growth and unity in Nigeria. 
60 Morphological Features of Nigerian Pidgin in the Football Commentary

\section{References}

Akande, A. 2008. The Verb in Standard Nigerian English and Nigerian Pidgin English: A Sociolinguistic Approach. Ph.D. Dissertation, University of Leeds.

Akande, A. 2010. Is Nigerian Pidgin English English? Dialectologia et Geolinguistica 18, 3-22.

Akande, A. 2013. Code-Switching in Nigerian Hip-Hop Lyrics. Language Matters 44, 39-57.

Akande, A. \& L. Salami. 2010. Use and Attitudes towards Nigerian Pidgin English among Nigerian University Students. In R. Millar (ed.), Marginal Dialects: Scotland, Ireland and Beyond 70-89. Aberdeen: Forum for Research on the Languages of Scotland and Ulster.

Amao, T. 2012. The Use of Pidgin English as a Medium of Social Discourse among Osun State University Students. African Nebula $5,42-52$.

Aremo, B. 2004. An Introduction to English Sentences. Ibadan: Scribo.

Asiyanbola, A. 2012. Basic English Grammar for Universities. Lagos:

Olivetree Publishing Venture.

Balogun, T. 2013. In Defense of Nigerian Pidgin. Journal of Languages and Culture 4, 90-98.

Bauer, L. 2004. A Glossary of Morphology. Edinburgh: Edinburgh University Press.

Beard, A. 1998. The Language of Sport. London: Routledge.

Central Intelligence. 2020. Nigeria-The World Factbook. Available at $<$ https://www.cia.gov/the-world-factbook/countries/nigeria/\#peopleand-society>.

Chapanga, E. 2004. An Analysis of the War Metaphors Used in 
Spoken Commentaries of the 2004 Edition of the Premier Soccer League (PSL) Matches in Zimbabwe. Zambezia 31, 62-79.

Chovanec, J. 2009. Simulation of Spoken Interaction in Written

Online Media Texts. Brno Studies in English 35, 109-128.

Crystal, D. 2003. The Cambridge Encyclopedia of the English Language. Cambridge: CUP.

Deuber, D. 2005. Nigerian Pidgin in Lagos: Language Contact,

Variation and Change in an African Urban Setting. London:

Battlebridge.

Durodola, F. 2013. The Rising Popularity of Pidgin English Radio

Stations in Nigeria: An Audience Study of Wazobia FM, Lagos.

Unpublished M.A. Thesis, Rhodes University.

Faraclas, N. 1996. Nigerian Pidgin. London: Routledge.

Faraclas, N. 2004. Nigerian Pidgin English: Morphology and Syntax.

In E. Schneider et al. (eds.), Varieties of English: A Multi-Media

Reference Tool 340-367. Berlin: Mouton de Gruyter.

Faraclas, N. 2012. Nigerian Pidgin. In B. Kortman \& K. Lunkenheimer

(eds.), The Mouton World Atlas of Variation in English 417-432.

Berlin: De Gruyter Mouton.

Ferguson, C. 1983. Sports Announcer Talk: Syntactic Aspects of

Register Variation. Language in Society 12, 153-172.

Hockett, C. 1947. Problems of Morphemic Analysis. Linguistic Society of America 23, 321-343.

Hockett, C. 1954. Two Models of Grammatical Description. Word 10, 210-234.

Igboanusi, H. 2008. Empowering Nigerian Pidgin: A Challenge for Status Planning. World Englishes 27, 68-82.

Ihemere, K. 2006. A Basic Description and Analytical Treatment of Noun Clauses in Nigerian Pidgin. Nordic Journal of African Studies 15, 296-313.

Mann, C. 1993. Polysemic Functionality of Prepositions in Pidgins 
62 Morphological Features of Nigerian Pidgin in the Football Commentary

and Creoles: The Case of 'fo' in Anglo-Nigerian Pidgin. In F. Byrne \& J. Holmes (eds.), Atlantic Meets Pacific: A Global View of Pidginisation and Creolization 57-67. Amsterdam: John Benjamins.

Mathieson, P. 2016. Linguistic Features of 'Alternative' Football Commentary: A Comparative Register Analysis. Imperial Journal of Interdisciplinary Research 2, 59-67.

Mazzoli, M. 2017. Language Nativisation and Ideologies in Ajégúnlè (Lagos). Language \& Communication 52, 88-101.

Mensah, E. 2011. Lexicalization in Nigerian Pidgin. Concentric: Studies in Linguistics 37, 209-240.

Mensah, E. 2012. Grammaticalization in Nigerian Pidgin. Íkala, Revista de Lenguaje y Cultura 17, 167-179.

Mowarin, M. 2012. Question-word Interrogatives in Nigerian Pidgin. The Journal of the Linguistic Association of Nigeria 15.1-2, 95104.

Osakwe, M. \& M. Mowarin. 2010. The Internal Structure of the Noun Phrase in Naija. Conference Proceeding on Nigerian Pidgin. Ibadan: University of Ibadan.

Osisanwo, A. 2012. A Morphological Analysis of Nigerian Pidgin: The Example of Selected Advertisement Jingles. The Journal of the Linguistic Association of Nigeria 15, 41-54.

Osoba, J. 2014. The Use of Nigerian Pidgin in Media Adverts. International Journal of English Linguistics 4, 26-37.

Osoba, J. 2015. Analysis of Discourse in Nigerian Pidgin. Journal of Universal Language 16.1, 131-159.

Osoba, J. 2018. Power in Nigerian Pidgin (NP) Discourse. Journal of Universal Language 19.1, 1-32.

Osoba, S. 2004. Word-Formation Processes in English and Nigerian Pidgin. In A. Adetugbo et al. (eds.), The Domestication of English in Nigeria 231-247. Lagos: University of Lagos Press. 
Pérez-Sabater, C. et al. 2008. A Spoken Genre Gets Written: Online Football Commentaries in English, French, and Spanish. Written Communication 25, 1-27.

Plag, I. 2003. Word-Formation in English. Cambridge: CUP. Quirk, R. et al. 1985. A Comprehensive Grammar of the English Language. London: Longman.

\section{Appendix}

Croatia na the second team wey go enter the world cup final after them use play-off take qualify for this world cup. we dey see Ogbonge Ogbonge people them, people wey carry weight for inside this matter of football things Vladimir Putin the ogapresido of Russia and Gianni Infantino Oga presido of Fifa two of them don dey collabo and them go dey talk to theirself. Them dey try to want enjoy this game. But one sure thing wey I know say two of them go happy for na say yes so far this world cup don make sense. And you want talk say for their two them go still want enjoy how this players go use give them better entertainment. Mbappe go want try get another goal for himself for this world cup e no go bad if him go fit score another one here but then France gats defend this one first from Croatia as Umtiti go still do this work, now the bross don dey para e be like say vex don dey enter him blood because him defenders no dey helep him matter so far for this match na only him one we don dey see wey dey clear every ball wey Strinic dey want put inside the box. So him don dey para for him defenders say make them shine their eye ooh! This one no be the one wey you go want dey form big boys for front them dey attack them no go come defend, them need to defend. The highest goal scorer so far between this two Obodo nations na Mbappe as e be like one 
player for Croatia now dey round and I sure say no be ball wey near am but e be like say na something wey happen when ball no dey him leg. As the bross go dey check him eye whether blood deycomot. And Lukas Hernandez go helep am stand up as he go see again, pass master and give Matuidi shallow there, so far for this competition him Luka Modric him don score two goals as him na one of the highest goal scorers for Croatia so far then another person wey don score two goals naPeristic but for France at least them get two players wey don scores 3, 3 goals each. You want talk about Antoine Griezman now and Klian Mbappe now wey want try pursue this ball now. Olivier Giroud no go fit continuate with that matter because the paraporism of Croatia e be like e dey worry France so far for this match.

Perisic!, Perisic he make sure say him cross make sense. he balance he look well, he hammer the shot as siririwerere he blow am meet Hugo Lloris for equalizer... You want talk say na him number 3 goal for this final na him be that, the brossdey score important, important goals, naperisic be that for you. When I say goal dey important na Ivan Perisic because remember against England na him still score their equalizer today the bross don do am again he don do am again.

So you want talk say for BlaiseMatuidi, him get chance to still help France maintain their Kakaralisation for mid field... I sure say him no go want make that mistake again the second time... As him santo that one now troway... Mbappewey don turn to the second youngest player ever wey go score world cup goal for final as Toliso now go find Giround but Brozovic been collect that ball and him win free kick for inside the half... chance here now for Vrsaljko, Vrsaljko go rush sonch the pass now to give Perisic, nice cross inside the area but Varane dey there to nod troway. 